\title{
Cuidados de enfermagem aos pacientes politraumatizados atendidos na emergência
}

RESUMO Objetiva-se a reconhecer os cuidados desenvolvidos pelos profissionais de enfermagem no serviço de emergência de um hospital geral do Alto Vale do Itajaí, do estado de Santa Catarina, Brasil, durante a assistência prestada aos indivíduos vítimas de politraumatismo. Trata-se de um estudo qualitativo, de campo, de caráter descritivo. Fizeram parte dos sujeitos da pesquisa 07 Enfermeiros lotados no setor de emergência. Após análise exaustiva dos dados, estes foram organizados em 3 categorias: Principais Cuidados dos Profissionais de Enfermagem na Atenção ao Trauma Múltiplo; Instrumentos Utilizados que Norteiam a Prática; e Aquisição de Conhecimento do Enfermeiro em Torno do Trauma. Verificou-se que o tempo de atendimento na instituição pesquisada ultrapassa na maioria das vezes os 60 minutos, não sendo possível prestar todos os cuidados recomendados nesse tempo crítico conhecido mundialmente como Golden Hour, e constatamos que nem todos os profissionais de enfermagem atendem totalmente o que é preconizado em protocolos como - $A B C D E$ do trauma, legislações vigentes, e a sistematização da assistência de enfermagem que é um método cientifico utilizado pelo enfermeiro para guiar o seu cuidado, este método é realizado pulando etapas ou de forma informal.

Palavras-chaves: Enfermagem em Emergência; Cuidados de Enfermagem; Traumatismo Múltiplo.

ABSTRACT | It aims to recognize the care provided by nursing professionals in the emergency service of a general hospital in Alto Vale do Itajaí, in the state of Santa Catarina, Brazil, during the care provided to individuals who are victims of multiple trauma. This is a qualitative, field, descriptive study. The study subjects were 07 Nurses assigned to the emergency department. After exhaustive analysis of the data, they were organized into 3 categories: Main Care of Nursing Professionals in Attention to Multiple Trauma; Instruments Used to Guide the Practice; and Acquisition of Nurses' Knowledge Around Trauma. It was found that the time of attendance at the researched institution in most cases exceeds 60 minutes, not being possible to provide all the care recommended in this critical time known worldwide as Golden Hour, and we found that not all nursing professionals fully attend to what it is recommended in protocols such as the $A B C D E$ of trauma, current legislation, and the systematization of nursing care, which is a scientific method used by nurses to guide their care, this method is performed skipping steps or informally.

Keywords: Emergency Nursing; Nursing Care; Multiple Trauma.

RESUMEN | Su objetivo es reconocer la atención brindada por los profesionales de enfermería en el servicio de emergencia de un hospital general en Alto Vale do Itajaí, en el estado de Santa Catarina, Brasil, durante la atención brindada a las personas que son víctimas de múltiples traumas. Este es un estudio cualitativo, de campo, descriptivo. Los sujetos del estudio fueron 07 enfermeras asignadas al departamento de emergencias. Después de un análisis exhaustivo de los datos, se organizaron en 3 categorías: Atención principal de los profesionales de enfermería en atención al trauma múltiple; Instrumentos utilizados para guiar la práctica; y Adquisición del conocimiento de las enfermeras sobre el trauma. Se descubrió que el tiempo de asistencia a la institución investigada en la mayoría de los casos excede los 60 minutos, no siendo posible brindar toda la atención recomendada en este momento crítico conocido mundialmente como Hora Dorada, y descubrimos que no todos los profesionales de enfermería atienden completamente lo que Se recomienda en protocolos como el $A B C D E$ de trauma, la legislación actual y la sistematización de la atención de enfermería, que es un método científico utilizado por las enfermeras para guiar su atención, este método se realiza omitiendo pasos o de manera informal.

Descriptores: $\mathrm{xx}$

\section{Rubyely Caroline Will}

Enfermeira. Bacharel em Enfermagem pelo Centro Universitário para o Desenvolvimento do Alto Vale do Itajaí - UNIDAVI, Rio do Sul, SC. Enfermeira assistencial na UTI do Hospital Bom Jesus, Ituporanga, SC.

\section{Rosimeri Geremias Farias}

Enfermeira. Mestre em Enfermagem pela Universidade Federal de Santa Catarina UFSC, Florianópolis, SC. Doutoranda em Ciências daSaúde pelaFaculdade deMedicina do ABC, Santo André, SP. Professora Titular, coordenadora do Curso de Graduação em Enfermagem e Coordenadora do Núcleo de Práticas da Saúde do Centro Universitário para o Desenvolvimento do Alto Vale do Itajaí - UNIDAVI, Rio do Sul, SC. Enfermeira da Prefeitura Municipal de Petrolândia, SC.

\begin{abstract}
Heloisa Pereira de Jesus
Enfermeira. Especialista em Emergência e Terapia Intensiva pela Universidade do Sul de Santa Catarina, Palhoça, SC. Mestranda em Ciências da Saúde pela Faculdade de Medicina do ABC, Santo André, SP. Professora Titular e coordenadora das práticas assistenciais no Centro Universitário para o Desenvolvimento do Alto Vale do Itajaí - UNIDAVI, Rio do Sul, SC. Gerente de Enfermagem do Hospital Dr Waldomiro Colautti, Ibirama, SC.
\end{abstract}

\section{Thayse Rosa}

Enfermeira. Mestre em Enfermagem pela Faculdade Israelita de Ciências da saúde Albert Einstein - FICSAE, São Paulo, SP. Doutoranda da Universidade do Extremo Sul Catarinense - UNESC, Criciúma, SC. Professora Titular no Centro Universitário para o Desenvolvimento do Alto Vale do Itajaí - UNIDAVI, Rio do Sul, SC. Professora Titular na Faculdade de Santa Catarina FASC, São José, SC. 
INTRODUÇÃO

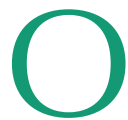
trauma pode ocorrer devido a inúmeros fatores, como quedas, acidentes de trânsito e violência, quando não mata, pode ser incapacitante e constituir-se num grande problema de saúde pública no Brasil e no mundo. Nessas situações, a aplicação dos cuidados de enfermagem é indispensável para melhorar a qualidade do serviço multiprofissional prestado na emergência, pois, do mesmo modo que promove a diminuição de sequelas passíveis de inabilitar o paciente, previne complicações e auxilia na recuperação do indivíduo visando o retorno às atividades diárias.

Anualmente 5,8 milhões de pessoas morrem por trauma em todo o mundo, o que corresponde a $10 \%$ de todas as causas de morte e, sem as devidas intervenções, prevê-se que esta proporção aumentará até 2030. Os traumas respondem também pela maioria de incapacitações permanentes. A maior parte dos traumas ocorre entre pessoas de 5 a 44 anos, ou seja, crianças, jovens e adultos jovens ${ }^{(1)}$.

No Brasil, de acordo com dados do DATASUS $^{(2)}$, anualmente 130 mil pessoas morrem por trauma e 450 mil ficam com sequelas graves, como: incapacidade para deambular, complicações na fala, dificuldades em pronúncias, em estudar ou ainda em exercer alguma atividade. Os acidentes de trânsito e a violência urbana são as principais causas de traumas.

Portanto, o objetivo desse estudo é reconhecer os cuidados desenvolvidos pelos profissionais de enfermagem no serviço de emergência de um hospital geral do Alto Vale do Itajaí, Santa Catarina, Brasil, na realização da assistência aos indivíduos vítimas de politraumatismo.

Sendo assim, este estudo possibilita conhecimento aos profissionais, norteando os cuidados de enfermagem ao politraumatizado com o propósito de manter ou restaurar a capacidade funcional e cognitiva, monitorar a evolução clínica e reduzir as taxas de mortalidade através da prevenção de agravos a saúde do indi- víduo, a fim de proporcionar então maior grau de independência ao indivíduo vítima de múltiplos traumas e resultando em uma menor incidência de gastos públicos, pois de acordo com as estatísticas apresentadas

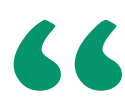

\section{No Brasil, de acordo com dados do DATASUS ${ }^{(2)}$, anualmente 130 mil pessoas morrem por trauma e 450 mil ficam com sequelas graves, como: incapacidade para deambular, complicações na fala, dificuldades em pronúncias, em estudar ou ainda em exercer alguma atividade. Os acidentes de trânsito e a violência urbana são as principais causas de traumas.}

em relação ao trauma, o tema é considerado um problema de saúde pública.

Diante de tal situação, questiona-se: Quais os cuidados desenvolvidos pelos enfermeiros na assistência aos pacientes politraumatizados em uma unidade de urgência e emergência de um hospital geral privado, do Alto Vale do Itajaí, no estado de Santa Catarina, Brasil?

\section{METODOLOGIA}

Trata-se de um estudo com abordagem qualitativa, de campo, descritivo que busca reconhecer os cuidados de enfermagem prioritários prestados às vítimas de politraumatismo pelo profissional enfermeiro, que trabalha no setor de emergência.

A pesquisa ocorreu na unidade de emergência de um Hospital Geral de grande porte localizado no Alto Vale do Itajaí, no estado de Santa Catarina, Brasil. Trata-se de uma instituição privada, filantrópica, mantida pela Fusavi. O hospital em questão é referência em várias especialidades de alta complexidade, atende 28 cidades, as quais juntas somam mais de 300 mil moradores.

Foram convidados para esta pesquisa a totalidades de 10 enfermeiros, lotados na unidade de emergência, com base nos critérios de inclusão os quais foram estabelecidos em: Profissionais que tenham mais de 06 meses de experiência e que atuassem diuturnamente no período da referida pesquisa. Após a pesquisadora ler e explicar a voluntariedade da participação, aceitaram receber o Termo de Consentimento Livre e Esclarecido (TCLE), e formalizaram o aceite procedendo à assinatura. Com base nos critérios de exclusão, quais sejam: Enfermeiros que não fosse possível o contato após 3 tentativas; que não tivessem interesse em participar da pesquisa e profissionais que estivessem de férias, licença ou de atestado durante o período de coleta de dados, fatores que resultaram nas 07 participantes informadas, não identificadas nesta pesquisa. 
Foram respeitados os preceitos éticos conforme determinação constante da Resolução n. ${ }^{\circ} 466$ de 12 e dezembro de 2012, implementada pelo Conselho Nacional de Saúde, o qual dispõe sobre os testes e pesquisas realizadas com seres humanos e dos direitos que lhes são assegurados, assim como, a própria comunidade científica e o Estado, tanto em termos individuais como coletivos. Houve o encaminhamento do projeto para o parecer do Comitê de Ética em Pesquisa (CEP) do Centro Universitário para o Desenvolvimento do Alto Vale do Itajaí- UNIDAVI, onde, após sua devida aprovação, número do Parecer: 2.719.988, iniciou-se a coleta no mês de setembro do corrente ano. Foi utilizado como instrumento de coleta de dados um questionário aberto, elaborado pelas pesquisadoras, contendo nele 21 perguntas. Entregue no mês de setembro do corrente ano também aos Enfermeiros lotados no setor da emergência do local de estudo, e que atenderem aos critérios de inclusão e exclusão, o instrumento foi preenchido pelos sujeitos de pesquisa no horário de em que estavam mais disponíveis, ressaltando que em qualquer momento o entrevistado poderá desistir da pesquisa.

A pesquisadora retornou em cada turno de trabalho após 3 plantões conforme combinado com os pesquisados para o recolhimento do questionário, porém aqui ocorreu uma dificuldade em recoIher esse instrumento pois as pesquisadas demoraram a preenchê-lo devido à grande demanda de atendimentos nesse setor, sendo necessário dar-lhes um tempo maior para preenchimento. Após a coleta as respostas foram transcritas e analisadas conforme interpretação de dados proposta por Bardin ${ }^{(3)}$, sendo que tais respostas permanecerão de posse do investigador por cinco (05) anos, e após esse prazo, serão descartadas.

Todavia juntamente com a literatura e em consonância com a teoria de Wanda de Aguiar Horta, as respostas foram correlacionadas. Desta forma, as respostas adquiridas foram organizadas em um banco de dados no Excel para melhor visualização e analise exploratória dos elementos. Desta coleção de dados emergiram as categorias que foram abordadas.

\section{RESULTADOS E DISCUSSÃO}

A população que compõe a presente pesquisa é composta por 07 dos 10 enfermeiros convidados a participar, foram retiradas da pesquisa com base nos critérios de exclusão, 01 que estava no período de férias e 02 negaram-se participar do estudo.

Todas as pesquisadas nesse estudo eram do sexo feminino. Sendo os turnos de trabalho nesse setor manhã, tarde e noite, das pesquisadas 01 é atuante em todos os turnos (varia o período), outras 02 atuam no período da manhã, 01 no período da tarde apenas, e as outras 03 no período da noite.

Quanto à idade do público alvo da pesquisa, o perfil dos sujeitos da pesquisa mostram 01 enfermeira, dos 20 a 29 anos, 02 enfermeiras dos 30 aos 39 anos e 04 enfermeiras acima dos 40 anos. Quanto ao tempo de atuação na área de urgência e emergência, há profissionais entre 09 meses e 10 anos de vivência no referido setor de pesquisa, sendo que duas atuam nessa área a menos de 1 ano, quatro atuam com tempo inferior a 5 anos, e duas com tempo inferior a 10 anos. Quando analisamos o período de atuação em urgência e emergência considerando experiências prévias em outras instituições, o resultado mostra que 01 pesquisada possui 08 anos de experiência em outra instituição, 02 com tempo inferior há 01 ano e as outras 04 não possuíam experiência em setores de pronto atendimento de outras instituições. Se considerarmos o tempo de atuação profissional de cada enfermeira somando o tempo de experiência nessa e em outras instituições, nenhuma delas possui o tempo inferior a 01 ano na área.

Quanto aos títulos de qualificação profissional, dos sete 07 participantes, a maioria possui especialização, sendo 04 em Urgência e Emergência, 01 em Cardiologia, 01 em Auditoria; e 01 não possui especialização.
A próxima etapa da análise e interpretação dos dados ocorreu após organização e leitura exaustiva dos resultados, para melhor compreensão elaboradas as categorias a seguir: Principais Cuidados do Profissional de Enfermagem na Atenção ao Trauma Múltiplo; Instrumentos que Norteiam a Prática; e Aquisição de Conhecimento do Enfermeiro em Torno do Trauma.

PRINCIPAIS CUIDADOS DOS PROFISSIONAIS DE ENFERMAGEM NA ATENÇÃO AO TRAUMA MÚLTIPLO

As áreas de Urgência e Emergência requerem do profissional enfermeiro a forma diferenciada do padrão tradicional de modelo Biomédico, organizado por rotinas e protocolos para o guiarem. $\mathrm{O}$ atendimento a ser prestado na emergência é uma assistência que está direcionada aos portadores de quadros agudos, de natureza clínica, traumática ou psiquiátrica. Diante de uma emergência, a Enfermagem tem como dever estabelecer prioridades na assistência em acordo com a avaliação primária da vítima, garantindo a identificação e o tratamento das situações que ameaçam a vida.

Os principais cuidados prestados por equipe de profissionais de enfermagem no momento do atendimento a vítima de politraumatismo, segundo duas enfermeiras do setor são em função do ABCDE do trauma e outras condutas conforme as falas:

"Seguir o ABCDE do trauma. Puncionar AVP de grosso calibre (dois acessos), monitorização, sondagens orogástrica e vesical, cuidados com vias aéreas, oxigenoterapia e auxilio na intubação SN. Coleta de exames e encaminhamento aos exames de imagem" (Enfermeira 4).

"Vias aéreas, Respiração e ventilação, Circulação e controle de hemorragia, Avaliação do estado neurológico, expor o paciente (despir o paciente, mas evitar hipotermia" (Enfermeira 7). 
O paciente politraumatizado é tido como prioritário, o atendimento sequencial destinado a este tipo de paciente segue o método "ABCDEs", este método ordena as medidas especificas da avaliação, e quais as intervenções correspondentes que devem ser adotadas. Essa proposta tem por origem o programa ATLS, que enfoca que o trauma tem um alto índice de mortalidade de acordo com uma cronologia previsível. O ATLS é adotado como padrão de cuidados a vítimas de traumatismos, e deve ser aplicado na primeira hora do início do atendimento, por profissionais de múltiplas áreas, sendo utilizado tanto em traumas nos grandes centros e em zonas rurais. $\mathrm{O}$ método foi desenvolvido de modo simples e objetivo para avaliação e tratamento das vítimas de traumas, visando identificar de maneira correta e rápida as condições de risco de vida ${ }^{(4)}$.

Para outras três pesquisadas referem se dar através de:

"Monitorização. Avaliar nível de consciência. Exame físico. Realizar classificação de risco. Acesso venoso periférico e medicação" (Enfermeiras 1; 3; 5).

A resposta dada por essas outras três enfermeiras atende parcialmente o que é dito pelos estudos científicos do que se deve fazer mediante a uma vítima de trauma múltiplo.

A equipe de profissionais de uma unidade de urgência e emergência tendem a atuar em equipe, juntamente com a equipe médica da mesma unidade, ou inicialmente com equipe que prestou o primeiro atendimento e condução da vítima até a unidade, utiliza-se de atendimento sincronizado para avaliação do paciente vítima de trauma, onde na prática a enfermagem de emergência é inteiramente ligada à competência clínica, deve ter um olhar global, desempenho holístico e total do paciente. A enfermeira de emergência é capacitada para estabelecer prioridades, no momento do atendimen- to, organizando e dando sequência aos protocolos de avaliação primária ${ }^{(5)}$.

Estes autores ${ }^{(5)}$ afirmam ainda que os enfermeiros em serviços de emergência assistem a vítima juntamente com o médico, preparando e administrando medicamentos, viabilizando o cliente em relação à execução de exames, instalando sondagens nasogástrica, nasoenteral e vesicais, realizando curativos de maiores complexidades, instrumentando para intubação, analisando os sinais vitais e evoluindo as vítimas em seu prontuário para que não sejam perdidos dados inerentes à assistência prestada.

As enfermeiras pesquisadas respondem com cuidados adequados perante ao primeiro atendimento à vítima de múltiplos traumas, porém, a depender do profissional que os executa realizam de forma incompleta, constatamos que esses cuidados ainda não estão padronizados entre esses profissionais de enfermagem. A enfermagem em assistência de pacientes vítimas de traumas necessita de uma imediata e completa avaliação, sincronizada e sequenciada durante ao atendimento, devendo ser essa assistência global e completar todos os passos do tratamento a politraumatizados. Um doente em tratamento de traumas múltiplos, além de necessitar de uma avaliação rápida das lesões, onde tempo é essencial, prestar uma abordagem sistematizada facilita e organiza o trabalho, e ainda caso haja necessidade de revisar a abordagem aplicada se esta é padronizada, evita erros da equipe, podendo ser realizada por todos os membros com homogeneidade.

Quando analisamos os cuidados de enfermagem mais complexos relatados pelas enfermeiras, em sua maioria, mencionam que encontram dificuldade com algum tipo de trauma, ressaltando os que envolvem o sistema nervoso central ou com um público em especial, como evidenciado na fala a seguir.

"Traumas envolvendo gestantes. Traumas de coluna. Hemor- ragias cerebrais. Traumas com choque hipovolêmico. Neural" (Enfermeira 3).

O objetivo do atendimento à vítima de trauma múltiplo é dirigido à preservação do equilíbrio fisiológico da vítima, a preservação da coluna cervical é primordial, já que esse trauma poderá, devido a provável lesão, desencadear sequelas permanentes. Os traumas cervicais normalmente são permanentes, o que modifica radicalmente as condições de trabaIho e qualidade de vida do indivíduo ${ }^{(6)}$.

A avaliação primária e a conduta na gestante não diferem da realizada em outros pacientes traumatizados, mas as mudanças anatômicas e fisiológicas da gestação podem levar a diferenças no tipo de lesão, modificar a resposta ao traumatismo e demandar alterações nas manobras de ressuscitação, dificultando o diagnóstico e o tratamento. Envolvem o aumento do débito cardíaco e do volume sanguíneo, levando a um estado de hipervolemia e hemodiluição, é mais suscetível à hipotensão na posição supina, por compressão aortocava, necessitando assim manter o útero deslocado lateralmente, a diminuição da motilidade gastrintestinal e a diminuição da competência do esfíncter gastroesofágico aumentam o risco de aspiração de conteúdo gástrico para as vias aéreas, sendo a descompressão gástrica de extremo valor na gestante, e ainda as modificações neurológicas da gravidez levam à diminuição da necessidade de várias drogas anestésica. O objetivo primordial do tratamento é estabilizar a condição materna, pois o melhor tratamento para o feto é a reanimação materna ${ }^{(6)}$.

Na avaliação secundária, após a estabilização, incluem exame físico detalhado, avaliação dos batimentos cardíacos fetais e monitoração fetal. E, ainda no exame do abdômen, deve-se observar se há presença de equimose em baixo ventre, $\mathrm{O}$ que indica uma possível lesão de bexiga e útero. No exame ginecológico, deve-se avaliar a presença de rotura de membra- 
nas, sangramento, lacerações vaginais e presença de fragmentos ósseos, os quais podem indicar uma fratura pélvica ${ }^{(6)}$.

O choque hipovolêmico em pacientes politraumatizados leva ao óbito muita das vezes quando suas causas não são tratadas, tornando a intervenção precoce sobre as possíveis lesões o principal fator de melhora no prognóstico desses pacientes, as medidas necessárias para controle e correção do choque hipovolêmico são o reconhecimento de sua existência, a identificação de sua causa o controle definitivo do sangramento, a restauração de um volume circulante adequado e a correção dos desequilíbrios causados ${ }^{(7)}$.

O choque neurogênico está associado entre hipotensão e bradicardia, a lesão das vias eferentes do sistema nervoso simpático medular e a consequente vasodilatação dos vasos viscerais e das extremidades, associadas a perda do tônus simpático cardíaco impossibilita a elevação da frequência cardíaca, é uma condição rara abaixo da vertebra torácica 6, a reposição de líquidos deve ser cautelosa nesse tipo de choque para que não haja sobrecarga, e o uso de substancias vasopressoras devem ser consideradas como uma opção terapêutica ${ }^{(7)}$.

A dificuldade que se tem em estabilizar o paciente em exames é mencionada pela pesquisada:

"O que eu percebo é a dificuldade de manter o paciente grave estável durante a realização de exames de imagem (RX e tomografia). Todos os cuidados de enfermagem são complexos no atendimento ao paciente politraumatizado" (Enfermeira 4).

O atendimento intra-hospitalar oferecido inicialmente, mediante avaliação primária, interfere diretamente no resultado final para prognostico do paciente, mediante o exame secundário iniciado logo após exame primário, considera-se como avaliação completa do paciente politraumatizado. Contudo, é necessário observar o desfecho final da avalição secundária, a terceira fase de avalição que inclui exame neurológico, de forma que a equipe de saúde (médico, enfermeiro) responsável, acompanhe a evolução e sucesso do tratamento definitivo ${ }^{(8)}$.

A dificuldade no manejo de pacientes politraumatizados, aumenta com a complexidade de cada caso, observa-se que, nos casos mais graves, principalmente relacionados a múltiplas fraturas, a estabilidade do quadro do paciente não permanece por vezes por um período mínimo para realização dos exames, sendo que em casos de alta complexidade alguns exames imediatos passam para segundo plano por conta da possibilidade de risco imediato à mortalidade do paciente.

O paciente acometido de múltiplas fraturas demanda uma maior agilidade, pensamento lógico e racional da equipe, que deve trabalhar sequencialmente junta, onde todos os membros da equipe multidisciplinar desempenham papel de extrema relevância no atendimento e no momento que a avaliação não deve permitir erros.

Visto que os profissionais mencionam em suas respostas as suas dificuldades que em sua maioria são comuns a todos eles, ficando a sugestão de realizarem capacitações ou treinamentos para aperfeiçoamento de suas dificuldades de acordo com as necessidades trazidas pela equipe nesse atendimento. A complexidade do atendimento prestado às vítimas é preconizada mediante as necessidades de cada caso, já que os traumas podem ser múltiplos. O paciente politraumatizado exige total atenção da equipe e, em alguns casos, os cuidados devem levar em conta a dificuldade do atendimento, principalmente em relação aos pacientes com trauma craniano, gestantes, ou possíveis traumas cervicais. Nesses casos, a vítima é classificada pela complexidade do atendimento, sendo prioridade a rápida avaliação, bem como de forma particular são destinadas manobras imediatas para preservação da vida.

Dentre as enfermeiras dessa equipe, mediante a serem questionadas sobre a segurança em atender uma emergência com politraumatismo, a maioria delas se sente confiante, como podemos constatar na fala a seguir:

"Sim, com segurança e responsabilidade. Porque fazemos a associação do conhecimento científico e prática diária" (Enfermeira 1).

Uma das pesquisadas deixou de responder esse questionamento e foi identificado que uma se sente insegura e justifica que fica ansiosa perante a situação

"Falta de segurança, pois sinto ansiedade pela espera do que desconhecimento na sala de emergência" (Enfermeira 7).

A autoconfiança que um indivíduo possui é a possibilidade de, num determinado contexto, demonstrar crença no sucesso, nos conhecimentos, nas habilidades, está relacionada com a autoeficácia. Consiste no grau de convicção e êxito para se obter um resultado, funciona como um determinante no modo de ação, comportamento, organização, padrões de pensamento e reações ${ }^{(9)}$.

O trabalho desenvolvido de modo multidisciplinar por profissionais de enfermagem com experiência consolidada, minimiza temores individuais. A plena confiança e colaboração mútua entre os membros da equipe que compõem a unidade de emergência vem de modo a auxiliar o profissional, com tendências temerosas, diante de clareza e certeza de atuação.

Sabe-se que pacientes vítimas de traumas, em sua grande maioria, tendem a ter recuperação lenta e demorada, o que aumenta o tempo de permanência do mesmo em ambiente intra-hospitalar. Por conta disso, é relevante que os profissionais que inicialmente realizaram sua avaliação estejam devidamente seguros de sua atuação, mediante necessidades do indivíduo.

Trabalhar com questões de urgência e emergência envolve amplos conhecimentos sobres aspectos técnicos que se 
alinham dentre o ambiente das vítimas atendidas e os profissionais qualificados para o atendimento. Por meio da Teoria de Enfermagem de Wanda de Aguiar Horta, percebe-se que devem ser criadas estratégias para a qualificação da enfermagem para o atendimento de vítimas de trauma, sendo fundamental uma boa avaliação e decisão correta referente ao tratamento e manejo destes pacientes, e perante essa avaliação é importante dar um feedback para os profissionais sobre os protocolos estabelecidos para cada situação, dessa forma, serão capazes de realizar auto avaliação, se o que estão desempenhando está de acordo com os cuidados atuais de enfermagem. Pois sentir-se segura nem sempre quer dizer que prestam os cuidados adequados.

Os cuidados respiratórios, segundo o ATLS, estão descritos nas categorias A e B do $A B C D E$, onde inicialmente, é avaliada a permeabilidade das vias aéreas superiores e posterior a avaliação da ventilação através da inspeção, percussão, palpação e ausculta do tórax.

Durante o atendimento à vítima de múltiplos traumas, deve-se inicialmente assegurar a permeabilidade das vias aéreas e a integridade do sistema ventilatório e do sistema cardiovascular antes mesmo de dar início à avaliação neurológica, uma vez que diante de quaisquer alterações desses sistemas, implicaria não somente em risco iminente de vida como também insultos de caráter secundários ao sistema nervoso, logo, a correta identificação de intercorrências e o manuseio correto das vias aéreas são fatores importantes na prevenção de insultos secundários e melhoram o prognóstico dos pacientes.

A identificação da insuficiência respiratória, segundo três das enfermeiras, se dá através de sinais e sintomas presentes na vítima, sendo esses identificados através de:

"Verificando sinais de: alteração do sistema cardíaco, Cianose da pele, Sudorese e Confusão mental" (Enfermeira 7).

"Dessaturação, Dispneia in- tensa, atentar para os sinais e sintomas respiratórios, ausculta, perfusão" (Enfermeira 6).

"Baixa saturação. Ausculta estertores. Cianose extremidades e face" (Enfermeira 2).

Já as outras descrevem sinais de como identificar a Insuficiência respiratória e vão além, abrangendo para os cuidados a serem executados para assistência ao quadro como nas falas:

"Monitorização, Instalação de O2, Expansibilidade torácica" (Enfermeira 1).

"Monitorização, Instalação de 02, Expansão torácica" (Enfermeira 3).

"Verificar SSVV, avaliar e verificar saturação de O2, nível de consciência, adequar parâmetros e verificar necessidade de iniciar oxigenoterapia" (Enfermeira 4).

"Cabeceira elevada a $45^{\circ}$ se possibilidade, Prevenção do movimento de fratura de cervical, Glasgow 7 proceder intubação para proteção VA" (Enfermeira 5).

A insuficiência respiratória se define pela dificuldade de manter a ventilação autônoma pulmonar, esta condição clinica acomete inúmeros pacientes onde suas causas podem ser as mais diversas, é classificada em aguda e crônica, seu tratamento é determinado após a observação do quadro do paciente, a conduta médica é, por vezes, de modo paliativo, isso depende do quanto o trato respiratório está afetado e se a deficiência é definitiva ou patologia tratável ${ }^{(10)}$.

Nota-se que a identificação de sinais de insuficiência respiratória é uma prática habitual das enfermeiras desse setor, mesmo que não seja descrito detalhadamente em suas respostas, visto ainda que em sua maioria o foco está direcionado ao cuidado e procedimentos a serem realizados após identificarem ou para prevenção. Surgindo a necessidade de abrir espaço para discutir sobre o tema no se- tor, pois os sinais e sintomas abrangem mais do que alterações de sinais vitais, visto a importância de identificar esses sinais, prevenindo agravos e até mesmo o óbito da vítima.

A dificuldade respiratória de um paciente pode ser a causa da insuficiência respiratória, além de causar uma maior dificuldade de manejo do paciente, demanda para enfermagem uma necessária observação contínua e atenta. Pacientes que apresentam dificuldade respiratória estão mais aptos a paradas cardiorepiratórias. Os protocolos e padronização dos cuidados desses pacientes contribuem para uma assistência de enfermagem de modo holístico global, devendo seguir atendimento individuais, mas mantendo a observação do cliente como um todo.

No manuseio do paciente vítima de trauma, os cuidados circulatórios correspondem a letra $\mathrm{C}$ do ATLS, deve ser sempre considerado e tratado a fim de evitar complicações decorrentes de hemorragias. Toda vítima de trauma grave com sinais de instabilidade hemodinâmica deve ser considerada de etiologia hipovolêmica, a realização de exame físico rápido e preciso auxilia na identificação de sinais indiretos de perda sanguínea. Com diminuição do volume sanguíneo ocorre hipoperfusão tecidual de todo o corpo, podendo levar à diminuição do nível de consciência, vasoconstrição periférica com sinais de pele pálida e esbranquiçada podendo ser um sinal indireto de hipovolemia.

As soluções líquidas utilizadas na reposição volêmica destas vítimas são evidenciadas nas falas da pesquisadas:

\footnotetext{
"Soluções salinas, Ringer, Voluven. Posteriormente hemoterapia" (Enfermeira 4).

"Ringer, SF aquecido, Hemocomponentes" (Enfermeira 3).
}

O uso de soluções líquidas aquecidas em politraumatizados está relacionado a evitar caso de hipotermia, onde deverá ser realizada a promoção do aquecimento externo, podendo ser utilizados 
líquidos intravenosos aquecidos ou ainda gases respiratórios também aquecidos ${ }^{(11)}$.

Atualmente, no tratamento da reposição volêmica usa-se inicialmente até $1.000 \mathrm{m \ell}$ de solução cristalóide isotônica, como lactato de Ringer ou solução fisiológica 0,9\%, por ser uma solução barata, de fácil acesso e com raras repercussões deletérias, e no objetivo de prevenir a hipotermia essa infusão deve estar na temperatura de $39^{\circ} \mathrm{C}^{(7)}$.

Nos cuidados que podem ser adotados mediante ao politraumatizado grave, hipotenso e com acesso ruim, as enfermeiras em sua maioria têm concordância perante as medidas a serem tomadas evidenciando na fala:

"Manter paciente aquecido, puncionar veias jugulares, solicitar ao médico puncionar acesso venoso central e avaliar com ele necessidade de uso de drogas vasoativas. Controlar PA mediante monitorização de PAI " (Enfermeira 4).

"Puncionar 2 ou mais acessos, jugular externa quando periféricos difíceis, Punção intraóssea não realizamos pois não temos material adequado" (Enfermeira 5).

Na admissão do paciente, a aquisição de dois acessos venosos periféricos calibrosos assegura um fluxo adequado à administração de volume intravenoso, e ainda é relevante lembrar que o calibre do cateter está relacionado com a velocidade de infusão de fluidos intravenosos ${ }^{(7)}$.

Percebemos que não há um consenso entre as enfermeiras sobre a melhor prática quanto à reposição volêmica e tratamento da hipotensão. O uso de dois acessos venosos calibrosos em vítimas de politrauma atendem às recomendações científicas, bem como o cuidado de deixar o paciente aquecido durante a emergência, porém apenas uma enfermeira citou o uso da infusão de solução aquecida, que é utilizada com a finalidade de evitar hipotermia e danos ao paciente decorrente disso.
Diante de paciente politraumatizado grave, os cuidados e avaliação primária de enfermagem deverão ocorrer de forma precisa e eficaz. Com possibilidade de morte eminente, a enfermagem deve se ater rigorosamente aos protocolos de avalição e atendimento.

Segundo a teoria de Wanda Hor$\mathrm{ta}(12)$, todas as necessidades humanas básicas estão intimamente inter-relacionadas, fazendo parte de um todo, o ser humano. E é fundamental que se integre o conceito holístico do homem, ele é um todo indivisível, não é soma de suas partes. Para ela quando uma necessidade se manifesta, o faz por sinais e sintomas, que se denomina problemas de enfermagem. Como o problema circulatório que pode ser evidenciado por sinais e sintomas, demonstrando assim a complexidade do estudo da enfermagem.

O exame neurológico durante a avaliação primária corresponde à letra $\mathrm{D}$ do ATLS e, no que se refere aos cuidados neurológicos necessários no atendimento às vítimas politraumatizadas, entende-se que a avaliação e prestação de cuidados imediatos se fazem necessárias em razão da complexidade dos detalhes morfológicos do sistema nervoso, quanto à célula nervosa em si e ao seu arranjo anatômico, tal como a fisiologia do sistema nervoso, o qual possui características singulares, pois é de extrema importância à sobrevivência ou redução de sequelas ao paciente.

Em relação às condutas de enfermagem realizadas ou delegadas após a avaliação neurológica, as enfermeiras mencionam os cuidados e a monitorização do paciente, representadas nas falas a seguir:

" $<$ ou $=8-$ auxiliar na intubação + VMI em ambú + O2, Sondagem orogástrica para evitar broncoaspiração, Conter o paciente por precaução, verificar com médico necessidade de sedação, etc... Manter após liberação de maca rígida, administrar demais medicações" (Enfermeira 4).
"Monitorização, Acesso venoso, Controle de pupilas, Escala de Glasgow - Nível de consciência" (Enfermeira 3).

"Monitorização, AVP, Controle de pupilas, Escala de Glasgow" (Enfermeira 1).

"Monitorização de pupilas e consciência" (Enfermeira 5).

E ainda outra pesquisada menciona as ações do profissional enfermeiro.

"Acesso venoso 2 pelo menos bem calibroso, Vias aéreas, Coordenação geral e atendimentos de enfermagem, Monitorização, Sinais vitais" (Enfermeira 6).

Em caso de TCE se deve avaliar, caracterizar e registar os Sinais Vitais da vítima e ainda dar suporte de oxigênio, pois constitui um elemento vital para as células do corpo e, particularmente, para as células do sistema nervoso, que são muito sensíveis à sua diminuição. Nos TCE, o fornecimento deste gás encontra-se afetado tornando-se de primordial importância aumentar o seu fornecimento de forma a diminuir o sofrimento das células cerebrais, devendo ainda permeabilizar a via aérea, estar preparado para a eventualidade de vômitos, devendo evitar possível broncoaspiração, e estar preparado para a existência de convulsões, com contenção da vítima ${ }^{(13)}$.

As enfermeiras da unidade perante os resultados da avaliação neurológica da vítima politraumatizada determinam as condutas ou cuidados que exercem, de forma adequada para tal situação, ressaltando a importância da manutenção de vias aéreas no atendimento a esse tipo de vítima a fim de proteger contra os danos ao sistema nervoso.

Aos sinais de alerta em as alterações cranianas que requerem atendimento imediato três enfermeiras mencionam sinais alarmantes como nas falas.

"Confusão mental, rebaixamento do nível de consciência, 
agitação, alteração de pupilas, alterações de SSVV, edemas e hematomas periorbitais, otorragias" (Enfermeira 4).

"Pupilas anisocóricas a direita ou esquerda, Olhos de guaxinim, sem resposta verbal" $\mathrm{E}$ enfermeira 7 "FCC, coma, agitação, deformidade craniana, hematomas, palpebrais, sinal de guaxinim, dor na cabeça, sonolência" (Enfermeira 2).

Outras três enfermeiras mencionam sinais feitos na avaliação rápida de uma vítima:

"Sangramento visível, Alteração no nível de consciência, Alteração de pupilas" (Enfermeira 1; 3).

"Pupilas anisocóricas, midriaticas, Escala de coma de Glasgow $<7$ " (Enfermeira 5)

A hemorragia intracerebral espontânea (HIC) é uma importante causa de morbilidade e mortalidade em todo o mundo. Recentemente, tem existido uma tendência para terapêutica agressiva, quer médica quer cirúrgica, com uma visão diferente do prognóstico desta situação clínica. $\mathrm{Na}$ verdade, o tratamento médico agressivo e de excelência parece ter uma importância crucial no prognóstico da HIC, mesmo sem existir uma terapêutica específica para a hemorragia. É de extrema importância a correcção pronta das alterações da coagulação nos doentes com HIC. Assim, os doentes com alterações da coagulação por deficiência de factores ou por trombocitopenia devem ser imediatamente tratados com administração de factores de coagulação e plaquetas ${ }^{(14)}$.

Considerando que os sobreviventes do traumatismo craniano estão sujeitos a apresentar inúmeras sequelas provenientes deste mal, tais como deficiências e incapacidades temporárias ou permanentes, as quais podem implicar na interferência direta nas capacidades do indivíduo de desempenhar suas funções habituais, resta evidenciar que a identi- ficação de sinais de alteração craniana é importante nesse cenário ${ }^{(15)}$.

A exposição da vítima de trauma se dá na letra E do ATLS e esta inclui a remoção de todas vestimentas e é realizada na avaliação primária do paciente. Nesse momento, é realizada a rolagem do paciente removendo todas as vestes e exame da parte dorsal do corpo. Posteriormente, se faz a limpeza e medicação temporária das lesões, posicionamento de talas e tutores ortopédicos e, por fim, é coberto com manta térmica para prevenir a dispersão de calor.

Ao avaliarem os tipos de traumas que a vítima pode ter, as enfermeiras em sua maioria mencionam utilizar do mesmo método para avaliar a existência de possíveis traumas evidenciado na fala de

"Exame físico completo SSVV, relatos do ocorrido, demais avaliações" (Enfermeira 4)

A verificação dos sinais vitais, faz parte da composição de avalição e exame físico do paciente, a manutenção da sequência lógica de exames no manuseio de paciente politraumatizado possibilita manutenção da padronização do atendimento, um exame detalhado, auxilia na prevenção, sendo que um diagnóstico rápido mas errôneo poderá determinar o tempo de recuperação do paciente, bem como causar sequelas irreversíveis ao politraumatizado, mediante a realização de exame físico caso o paciente venha a apresentar alteração dos sinais vitais pode -se dizer que é um indicador das condições de saúde do mesmo.

No entanto, a certeza do enfermeiro quanto a sua atuação frente a situações, um julgamento clínico preciso minimiza erros, assim por consequência possíveis sequelas. O indivíduo responde diferentemente a problemas de saúde, um diagnóstico de enfermagem sobre o indivíduo passado despercebido na sua avaliação primária deve ser revisto com mais atenção e precisão na secundária. É importante manter um bom relacionamento com a equipe, o enfermeiro ao exercer sua capacidade de liderança faz com que os profissionais trabalhem na mesma simetria, o que facilita a colaboração de todos os componentes da equipe, bem como a rapidez e precisão no atendimento.

$A$ avaliação primária envolve a aplicação do ABCDE do trauma que se dispõe em: A (Airway) - abertura de vias aéreas e estabilização cervical; B (Breathing) - boa respiração e/ou ventilação; C (Circulation) - domínio da circulação; D (Disability) - avaliação neurológica; e E (Exposure) - exposição do corpo da vítima para uma melhor avaliação de outras lesões possíveis, não aparentes $\frac{(16)}{}$.

A avaliação secundária do paciente é realizada por completo, onde se vai detectar mais precisamente outras lesões que na avaliação primaria passaram despercebidas, pois avalia holisticamente a vítima de politrauma como um todo. Entrando ainda nessa avaliação, exames de imagens para uma compreensão melhor de algumas fraturas e outros achados ${ }^{(17)}$.

Aos cuidados de enfermagem prestados a vítima em situação de trauma múltiplo podemos observar que há divergências sobre os cuidados prestados pela equipe também na abordagem primária e secundária, mostrando que nem todos da equipe utilizam a abordagem, porém essa deveria ser uma conduta de toda a equipe para que seja um atendimento padronizado por todos os profissionais perante ao atendimento ao paciente politraumatizado. Dessas enfermeiras, apenas duas utilizam um guia para os cuidados a serem prestados. E em relação a avaliação da vítima as enfermeiras trazem uma concordância perante o que deve ser realizado sendo exame físico, sinais vitais, anamnese ou inspeção.

Para Horta ${ }^{(12)}$ a coleta de dados leva à identificação dos problemas de enfermagem, que é toda a situação e/ou condição apresentada pelo indivíduo, e que exija assistência profissional, e esse deve se dar através da realização do exame físico que tem por finalidade identificar problemas de enfermagem. Deve se iniciar com a ve- 
rificação de sinais vitais e posteriormente seguindo para a inspeção e palpação no sentido cefálo caudal, descobrindo uma região de cada vez, mantendo o restante do corpo coberto com o lençol.

O tempo entre a ocorrência de um trauma e o atendimento hospitalar constitui um fator decisivo na ocorrência de sequelas e até mesmo da mortalidade, uma vez que a maioria dos óbitos ocorre ainda na fase pré-hospitalar. É fundamental que os profissionais que prestam cuidados a esses pacientes tenham habilidades baseadas em evidências científicas, isso permite raciocínio clínico para uma rápida tomada de decisão fundamental nas primeiras horas críticas de atendimento ao paciente, dessa forma pode-se aumentar as chances de sobrevida do indivíduo da maneira menos sequelante possível.

Um dos aspectos abordados nesta pesquisa teve a finalidade de conhecer o tempo médio em que os pacientes chegam na unidade de urgência e emergência após a lesão. Neste contexto, o tempo que a vítima costuma chegar ao setor da emergência para três pesquisadas é variável, dependendo da localidade do trauma e o meio de transporte que é utilizado para trazer essa vítima até o hospital.

Em seguida, buscou-se saber o tempo médio que leva para iniciarem os cuidados de enfermagem intra-hospitalares. Para a maioria das pesquisadas os cuidados de enfermagem no atendimento a vítima de múltiplos traumas deve ser imediato ou se iniciar o mais breve possível devido aos riscos que podem trazer para a vítima. Nesse quesito, podemos observar as recomendações que aparecem nas falas a seguir:

"Quanto menor o tempo para os cuidados menos risco de sequelas e mais qualidade da assistência" (Enfermeira 1).

"Depende muito da gravidade do trauma, se trauma leve 1 hora, se trauma mais grave meia hora" (Enfermeira 5).

"Considero 2 horas - "de ouro" (Enfermeira 7).

Somente esta enfermeira mencionou em sua resposta a Golden hour, mostrando ter conhecimento da existência desse termo para o tempo crucial de atendimento. Embora ela tenha sido a única a ter citado a hora de ouro, está equivocada quanto ao tempo preconizado, essa definição é referente há 1 hora e não há 2 horas como citou a pesquisada.

Embora exista um consenso estabelecido entre todas as pesquisadas que o tempo que leva da lesão até a chegada do paciente na emergência é crucial, o mesmo não está acontecendo na prática, uma vez que os pacientes chegam em média 1 hora após a lesão e, dentro desse tempo, já deveria ter recebido os cuidados definitivos para que não aumentassem os riscos, não obedecendo as recomendações internacionais, muitos dos pacientes principalmente os que vêm fora da cidade receberão os primeiros atendimentos após a hora de ouro. Um protocolo incluindo as redes de apoio na atenção urgência e emergência referente aos pacientes politraumatizados poderia ser articulado integrando atendimento pré-hospitalar e hospitalar para que seja registrado tempo a tempo todos os procedimentos, tempo de transporte, entrega do paciente no hospital e finalização dos cuidados para realização das equipes e adequações das etapas que estão levando mais tempo.

O julgamento e execução dos cuidados prestados pelas enfermeiras atendem o que determina o ABCDE do trauma, porém há divergências entre as profissionais, pois esses não são padronizados dentre elas, não seguem a protocolos para guiarem o atendimento frente a esse quadro de múltiplos traumas, o que dificulta conduzir toda a equipe mediante a situação para a tomada e execução das decisões.

INSTRUMENTOS UTILIZADOS PARA ANÁLISE E CONDUTA

As evidências científicas nos mostram que o atendimento inicial ao paciente politraumatizado deve sempre seguir as orientações preconizadas pelo ATLS (Advanced Trauma Life Support), devendo ser padronizado por protocolos institucionais, ou até, podendo seguir protocolos estaduais ou nacionais desde que haja uma consciência coletiva do que está padronizado, ou qual documento existente em seu setor para o atendimento desses pacientes, ou seja, qual o passo a passo a ser seguido com a finalidade de ser executado de forma padronizada, possibilitando a continuidade da assistência prestada;

Contudo, a utilização de manuais e protocolos da instituição ou de fora dela para nortear o cuidado com vítimas de múltiplos traumas se dá por apenas três enfermeiras do setor evidenciado nas falas a seguir.

"Protocolos de atendimentos (ATLS). Literaturas médicas e de enfermagem específicas" (Enfermeira 4). "POP, Traumas e protocolos" (Enfermeira 6).

"ATLS" (Enfermeira 5).

Analisando os relatos acima, podemos verificar que essas três enfermeiras tentam buscar evidências científicas que sustentem sua pratica através de protocolos e demais literaturas que tratam sobre o tema. As demais enfermeiras referiram não utilizar e, até mesmo, uma enfermeira refere que ainda está em andamento o protocolo da instituição, e dentre essas duas não responderam ao questionamento, onde acreditamos que elas desconhecem, pois do contrário responderiam.

Quando avaliamos a prestação de cuidados na avaliação neurológica, que deve também estar embasada em documentos, os relatos trouxeram a Escala de Coma de Glasgow, onde todas as enfermeiras mencionam sua utilização, evidenciando através da fala a seguir:

"Escala de Glasgow (abertura ocular 1 a 4, resposta verbal 1 a 5 e resposta motora 1 a 6 pontos) total $=$ 15 ECG pontuação de 3 a 15. Avaliação das pupilas" (Enfermeira 4). 
E ainda uma das enfermeiras descreve que realiza a avaliação neurológica através da seguinte forma:

"Escala de coma de Glasgow, Abertura ocular espontânea, Comunicação verbal, palavras orientadas, inapropriadas, obedece aos comandos, descerebrando, decorticando ou movimentos preservados" (Enfermeira 1).

As escalas de avaliação, preferencialmente utilizadas como padrão, como a Escala de Resultados de Glasgow e a Escala de Avaliação de Deficiência, além de inúmeros outros testes neuropsicológicos, tratam-se de instrumentos imprescindíveis e de alto valor científico para a devida e mais precisa avaliação da capacidade funcional neurológica das vítimas de politraumatismo, em especial vítimas de TCE.

Constatamos nas falas realizadas perante a avaliação neurológica das vítimas de politraumatismo, que as profissionais da unidade têm conhecimento e concordância a respeito do instrumento a ser utilizado, a Escala de coma de Glasgow, na realização dessa avaliação, podendo identificar possíveis traumas no sistema nervoso a fim de evitar agravos.

Duas das pesquisadas não o realizam a SAE, fazem apenas a avaliação da vítima pois os fatos acontecem muito rápido e não é possível prestar essa sistematização formalizada, sendo possível no momento da emergência realizar apenas a avaliação da vítima e a assistência.

"No momento da admissão é tudo muito rápido, seguindo $\mathrm{AB}$ CDE do trauma, cuidados secundários, etc" (Enfermeira 4).

"Exame físico, suplementar" (Enfermeira 3).

Segundo a Resolução Cofen n. ${ }^{\circ}$ 358/2009 Art. $6^{\circ}$ ao qual dispõe sobre a Sistematização da Assistência de Enfermagem (SAE) e a implementação do (PE) "A execução do processo de enfermagem deve ser registrada formalmente ${ }^{\prime \prime(18)}$.

A necessidade de fazer um diagnóstico preciso previsto na SAE de enfermagem pode evitar vários problemas a vítima de múltiplos traumas, pois os sinais e sintomas que podem ter passados despercebidos na avaliação primária, devem ser percebidos com mais precisão na secundária, pelo exame ser mais detalhado. $\mathrm{E}$ os diagnósticos de enfermagem são um julgamento clínico sobre as respostas do indivíduo, da família ou da comunidade a problemas de saúde/ processos vitais reais ou potenciais que são levantados mediante a avaliação do paciente ${ }^{(19)}$.

A devida utilização do processo de enfermagem norteia o trabalho da enfermagem perante a assistência em saúde a um indivíduo, bem como orienta as ações de cuidado por meio de etapas sistematizadas e inter-relacionadas, permitindo a continuidade da assistência prestada. A teorista Horta ${ }^{(12: 13-14)}$ conceitua e enumera “[...] os instrumentos básicos indispensáveis à enfermeira para que aplique pronta e adequadamente o processo de enfermagem (PE) ou, em última análise, para que possa dar a assistência de enfermagem em qualidade e quantidade que se espera de um profissional".

Dessa forma, a teoria em estudo e análise demonstra servir de base e fundamento aos cuidados de enfermagem prestados ao paciente politraumatizado, para que recupere tanto seu equilíbrio, desenvolva sua reabilitação, quanto realize sua readaptação, num contexto em que tudo ocorra no âmbito biopsicossocial o mais breve e menos traumático possível(12), razão porque a Teoria em análise foi adotada e aplicada no Brasil.

\section{AQUISIČÃO DE CONHECIMENTO DO} ENFERMEIRO EMTORNO DOTRAUMA

O serviço de urgência e emergência visa prestar atendimento rápido e provisório aos casos de acidentes ou enfermidades imprevistas, onde outros níveis da assistência à saúde estariam impossibilitados de resolver, e é nesse sentido em que emerge a necessidade de aptidão e conhecimento, além de experiência e habilidade do profissional que lida com traumas múltiplos.

A conhecida teoria "tríade da competência $\mathrm{CHA}^{\prime \prime}$ mundialmente difundida na administração e gestão de pessoas, elenca que para o profissional ser competente no que ele faz ele precisa ter conhecimento, habilidades e atitudes conforme podemos observar na imagem.

Neste contexto, para que o profissional possa oferecer cuidados de enfermagem com boa qualidade é essencial que ele busque por conhecimento atualizado, padronizado em seu local de trabalho e com base nos protocolos e recomendações que utilizem evidências científicas. Sem essa base da pirâmide bem estruturada não há como sustentar a habilidade que nada mais é do que saber fazer o procedimento de enfermagem considerando a parte prática, ou seja, não há como ter boas práticas nos cuidados que fazemos se essa base da pirâmide não tiver bem estruturada e retroalimentada constantemente em forma de atualização. Seguindo essa mesma linha de raciocínio, mesmo que o profissional tenha atitude do querer fazer, se ele não tiver bem embasado, embora tenha intenção terá grandes riscos de cometer erros.

Por isso, elencamos a aquisição de conhecimento como um pilar fundamental para execução dos cuidados de enfermagem prestados aos pacientes politraumatizados de maneira competente. O aprendizado necessário para desenvolvimento das habilidades dos procedimentos de enfermagem envolvidos no atendimento das vítimas de politrauma, segundo três das pesquisadas se deu através da rotina de seu trabalho, e formação técnico-científica, como descrito nas falas a seguir.

"Curso Superior/ Estágios/ Práticas/ Seminários/ especialização/ congressos/ capacitação. No dia-a-dia dentro do ambiente de trabalho" (Enfermeira 1).

"Na graduação, "no dia-a- 
-dia", na pós-graduação, cursos e treinamentos". (Enfermeira 4).

"Treinamentos. Educação continuada. Especialização e cursos" (Enfermeira 6).

O profissional enfermeiro atualmente tem necessidade de se especializar e buscar caminhos para o desenvolvimento técnico-científico e deve sempre estar em busca de aperfeiçoamento, através de cursos, especializações, congressos e até mesmo o atendimento das emergências é uma oportunidade de este estar agregando conhecimento durante o exercício da profissão.

Analisando os relatos dessas 3 pesquisadas identificamos que elas contemplam as expectativas em busca de uma boa base teórica que sustentem sua prática. Porém duas pesquisadas mencionam que o aprendizado se deu na graduação e no trabalho apenas, conforme podemos observar nas falas a seguir:

"Durante a faculdade nos estágios e no trabalho" (Enfermeira 2).

"No estágio. No dia-a-dia" (Enfermeira 3).

As vivências durante o período de graduação dos profissionais enfermeiros proporcionam já ao acadêmico um considerável crescimento em sua área de atuação, através do qual se desenvolve o exercício da assistência em saúde, aliando a teoria à prática. Desse modo, as vivências proporcionam o aperfeiçoamento de técnicas e competências da equipe de enfermagem e do profissional enfermeiro, além de ampliar uma visão suplementar atuação em um serviço de saúde ${ }^{(20)}$.

Entretanto, o profissional se forma, os anos passam, e as condutas de enfermagem são atualizadas passando por constantes melhorias procedimentais, desta forma a atualização não deve ser uma escolha do profissional e sim um dever e compromisso com uma assistência de enfermagem de qualidade.

O enfermeiro na tentativa de garantir a qualidade do cuidado que está sob sua responsabilidade deve sempre se manter atualizado, pois os riscos caso isso não ocorra pode inferir diretamente no paciente, aumentando os riscos de sequela e morte, um profissional com conhecimento científico atualizado faz uso da prática já aperfeiçoada. Mais impactantes foram os relatos de duas das participantes, que afirmaram que o seu conhecimento foi obtido somente através da experiência em seu trabalho.

Contudo, só a vivência não é suficiente porque práticas podem ser realizadas de maneiras desatualizadas correndo o risco de um profissional ir passando para outro o que aprendeu no "boca a boca" sem rever os conhecimentos teóricos na cultura de que sempre foi assim, na prática você ganha a habilidade do procedimento, porém elas devem ser baseadas nos conhecimentos produzidos por estudos, uma vez que as evidencias científicas são dinâmicas na busca da melhor prática evidenciada como já discutido anteriormente. Em relação aos cursos na área de urgência e emergência para as profissionais do setorse possuírem interesse em se atualizar, seis dessas alegaram que a realização destes se dão através de recursos próprios, a exemplo, cita-se a fala da participante abaixo:

\section{"São custeados por mim" (Enfermeira 7).}

Sendo que somente uma das profissionais participantes respondeu que a instituição onde trabalha eventualmente a ajuda com os custos dos cursos:

"Depende, às vezes meio a meio". (Enfermeira 5).

O conhecimento é dinâmico e está em constantes mudanças, dessa forma, não devemos achar que esse conhecimento foi algo apreendido e que não são necessárias atualizações ao longo do tempo, porém, quando não há incentivo por parte da instituição de trabalho a busca por aperfeiçoamento se torna ainda mais difícil, pois além de requerer custos financeiros demanda de tempo desse profissional para se dedicar a estudos, impossibilitando- o de ampliar seu conhecimento para além da graduação, outro obstáculo para enfermagem gira em questão do piso salarial e desvalorização da categoria fazendo com que este profissional tenha que trabalhar muitas vezes em mais de um emprego, dificultando tempo disponível para as atualizações.

O cenário ideal seria um planejamento da instituição na busca da promoção de melhores práticas incentivando seus colaboradores, seja por capacitações produzidas no hospital, seja nos custeios de atualizações que ocorrem fora da instituição, concedendo folgas, ou limitando um número de horas mínima anuais que devem ser cumpridas pelo setor, entre diversas estratégias que podem ser planejadas pela gestão para alcançar que os cuidados sejam prestados de maneira padronizada e baseadas em evidências científicas.

Nesse aspecto, identificamos que as formas de aquisição de conhecimento por parte da maioria dos enfermeiros não atendem ao que se preconiza em diversas literaturas, da mesma forma que não possuem incentivos necessários para irem em busca de novos conhecimentos.

Segundo Horta $^{(12)}$ na enfermagem todos os conhecimentos e técnicas adquiridas fazem menção ao cuidado do ser humano, ou seja, explicam como atendê-lo em suas necessidades básicas. E ainda a enfermagem assiste o ser humano no atendimento de suas necessidades básicas, utilizando dos conhecimentos e princípios científicos das ciências físico-químicas, biológicas e psicossociais.

\section{CONCLUSÃO}

A presente pesquisa possibilitou a compreensão acerca dos cuidados de enfermagem fazendo a reflexão do que ocorre na prática com as recomendações internacionais por órgãos competentes.

O esforço por parte da enfermagem em trabalhar com a união dos conheci- 
mentos científicos à pratica é extremamente importante, quando se cuida de seres humanos, devendo observar para além dos aspectos clínicos, mas analisar a consequência que o trauma gera a essa pessoa dentro de sua realidade individual. A identificação de possíveis lesões incapacitantes secundárias ao trauma, que acarretará dificuldades ou mesmo impedirá o desempenho de uma determinada atividade para a vítima é importante no atendimento emergencial, pois poderá ocorrer sua prevenção e auxiliará na posterior reabilitação.

Analisando os resultados do trabalho demonstrou-se a importância do profissional enfermeiro, frente ao julgamento e execução dos cuidados prestados no atendimento emergencial a vítima politraumatizada.

Perante a avaliação do politraumatizado as pesquisadas concordam mediante ao que deve ser realizado sendo exame físico, sinais vitais, anamnese ou inspeção. E diante dos cuidados de enfermagem prestados por elas pode-se observar que há divergências em relação aos cuidados na abordagem primária e secundária, e dentre as pesquisadas apenas duas utilizam um guia para os cuidados a serem prestados à vítima.

Percebeu-se que a maioria dos cuidados atendem o que preconiza o ABCDE do trauma, porém, ainda há divergência entre profissionais sobre qual realizar primeiro ou como realizar, pois, a maioria dos profissionais não seguem nenhum protocolo para guiar o atendimento ao politraumatizado o que dificulta conduzir toda a equipe diante de situações emergenciais para tomada de decisões. Mesmo a maioria reconhecendo os cuidados dentro ABDCE, não fazem tais cuidados dentro da Golden Hour, ao que tange os cuidados que devem ser estabelecidos nessa hora, percebemos que não atendem a necessidade, pelo fato de passar de 60 minutos para prestar o primeiro atendimento até os cuidados definitivos, para que não aumente os riscos decorrentes do trauma. O conhecimento sobre a necessidade de atendimento imediato ao politraumatizado é evidenciado na maior parte dos pesquisadas, porém as condutas a serem tomadas nessa primeira hora de atendimento é divergente e não padronizada por todos os enfermeiros que trabalham nesse setor. Em sua maioria as profissionais não utilizam protocolos, POPs nem recomendação de literaturas para sustentar a sua prática, o que dificulta em alcançar melhoria da qualidade das práticas de enfermagem.

E ainda visto a necessidade do profissional se atualizar, se estes quiserem realizar estudos, em relação aos cursos na área de urgência e emergência, se possuírem interesse em se atualizar, se dão através de recursos próprios, eles têm de arcar com os custos para aperfeiçoamento e aprofundamento do conhecimento, pois não há incentivo da instituição de trabalho e ainda outro obstáculo para enfermagem se atualizar está em torno do piso salarial e desvalorização da categoria, onde por diversas vezes este profissional tem que trabalhar em mais de um emprego, dificultando tempo disponível para as atualizações. Por fim, evidenciou- se que esta pesquisa traz contribuições importantes para instituições de ensino superior, profissionais atuantes na área da saúde que busquem por estudar o tema e principalmente pacientes vítimas de politraumatismo.

\section{Referências}

1. Krug E. Traumas matam mais que as três grandes endemias: malária, tuberculose e Aids. Autor é diretor do Departamento de Prevenção De Traumatismos E Violências E Desabilidades da OMS em Conferência na OPAS/OMS no Brasil, 2013.

2. DATASUS. DEPARTAMENTO DE INFORMÁTICA DO SUS. Atendimento especializado na "Golden hour" é essencial para reduzir mortalidade e evitar sequelas em pacientes de trauma. Rev. DATASUS por dentro 2.0. Edição $\mathrm{n}^{\circ}$ 74. Julho de 2014.

3. Bardin L. Análise de conteúdo. Lisboa: Edições 70; 1988.

4. Dalcin RR, Cavazzola LT. Serviço de assistência médica de urgência. In: NASI, L. A. et al. Rotinas em pronto-socorro. 2.ed. Porto Alegre: Artmed; 2005.

5. Wehbe G, Galvão MC. Aplicação da liderança situacional em enfermagem de emergência. Rev Bras Enferm. 2005; 58(1).

6. Abib SCV, Perfeito JAL (Coord.). Guia de trauma. Barueri: Manole; 2012.

7. Ribeiro MAF. Fundamentos em cirurgia do trauma. Rio de Janeiro: Roca; 2016.

8. Albino RM, Riggenbach V. Atendimento hospitalar inicial ao politraumatizado. Arquivos Catarinenses de Medicina. 2004; 33(20).

9. Mazzo $A$, et al. Validation of the self-confidence scale of nursing care in urinary retention. Rev. Latino-Am. Enfermagem. 2015 out.; 23(5):814-820.

10. Pádua A, Alvares F, Martinez JA. Insuficiência respiratória. Medicina
(Ribeirão Preto. Online). 2003 dez.; 36(2/4):205-213.

11. Roloff $A$. Atendimento inicial em vitima de trauma. Enfermagem Brasil. 2007 mai./jun.; 6(3):205-212.

12. Horta WA. Processo de enfermagem. São Paulo: EPU; 1979.

13. Meira L, et al. Manual TAS - Emergências de trauma. Versão 2.0. Departamento de Formação em Emergência Médica (INEM), 2012. 14. Cerejo A. Hemorragia Intracerebral Espontânea. In: SPCI Sociedade Portuguesa de Cuidados Intensivos. Rev Port Med Int. 2011; 18(3). 15. Faria L. Sequelas do Traumatismo Craniano. LinkedIn, 2017.

16. Mattos LS. Avaliação do indivíduo vítima de politraumatismo pela equipe de enfermagem em um serviço de emergência de Santa Catarina. Revista Brasileira em Promoção da Saúde. 2012; 25:182-191.

17. Almeida LS. Perfil e conduta dos profissionais de enfermagem diante dos primeiros socorros em um paciente politraumatizado. Rev. Derecho y Cambio Social. 2016 out.

18. Conselho Federal De Enfermagem (COFEN). Resolução COFEN n. ${ }^{\circ}$ 358/2009, de 15 de outubro de 2009. Dispõe sobre a Sistematização da Assistência de Enfermagem e a implementação do Processo de Enfermagem em ambientes, públicos ou privados, em que ocorre o cuidado profissional de Enfermagem, e dá outras providências.

19. NANDA International. Diagnósticos de enfermagem da NANDA: definições e classificação 2009-2011. Porto Alegre: Atrmed; 2009.

20. Munhoz OL, et al. Atuação do enfermeiro em unidade de pronto socorro: relato de experiência. Biblioteca Lascasas, 2016. 